\title{
La excepción de la empresa en crisis (failing firm defence): La evaluación de las concentraciones de recuperación o saneamiento económico en la Unión Europea
}

Mario Antonio Pérez Molina 94

Universidad Centroamericana “José Simeón Cañas" El Salvador mperez@uca.edu.sv

\section{Resumen}

La Comisión Europea a fin de determinar la compatibilidad o incompatibilidad de las concentraciones de empresas de dimensión comunitaria ha de tener en cuenta criterios tanto concurrenciales como extraconcurrenciales. Precisamente, entre estos últimos se encuentra la grave situación financiera y económica que atraviesa la empresa objeto de adquisición. Con tal propósito se ha elaborado la doctrina de la empresa en crisis o failing firm defence, que faculta a la autoridad antitrust a declarar licitas aquellas operaciones de concentración, que pese a plantear problemas de competencia, son aptas para funcionar como medidas anticrisis de ciertas empresas que están obligadas a abandonar el mercado. El presente trabajo se propone estudiar dicha doctrina en el ámbito singular del control de las concentraciones de empresas en la Unión Europea.

\section{Palabras clave}

Excepción de la empresa en crisis / concentraciones de recuperación o saneamiento económico / control europeo de concentraciones de empresas / Reglamento 139/2004 / Directrices sobre Concentraciones Horizontales / Derecho europeo de Defensa de la Competencia / Unión Europea

\section{Abstract}

The European Commission to assess the compatibility or incompatibility of mergers with a community dimension has to consider different factors. Among them is the serious financial and economic situation of the target company. For this purpose has developed the failing firm defence, which enables the antitrust authority to allow those mergers, that despite raise competition concerns, are suitable to operate as anti-crisis measures. This paper aims to study this issue in the singular area of the European Merger Control.

\footnotetext{
${ }^{94}$ Este trabajo se enmarca dentro del Proyecto de Investigación de Excelencia del MICINN intitulado «Contratación mercantil y competencia empresarial: nuevas tendencias reguladoras y propuestas de conexiones normativas», del que son Investigadores Principales los Profs. Drs. Luis María MIRANDA SERRANO y Javier PAGADOR LÓPEZ. El autor es Doctor en Derecho. A su vez, es profesor de la Universidad Centroamericana, UCA de El Salvador y colaborador del Área de Derecho mercantil de la Universidad de Córdoba, España.
} 
Failing firm defence/ European Merger control/ EC Merger Regulation/ Horizontal Merger Guidelines/ concentrations between undertakings/ competition law/ European Union.

\section{Tabla de contenido}

I. Consideraciones preliminares. 2. La aplicación de la doctrina de la failing company en el Derecho antitrust europeo: origen y evolución histórica. 2.I Antecedentes históricos de la doctrina de la empresa en crisis en la Unión Europea. 2.2 La gestación de la failing company bajo el Reglamento 4064/89. 2.2.1 El asunto Aérospatiale-Alenia/De Havilland. 2.2.2 El asunto Kali+Salz/MDK/Treuhand. 2.2.3 El asunto BASF/Eurodiol/Pantochim. 3. Los presupuestos de la doctrina de la empresa en crisis en el actual Reglamento 139/2004 y en las Directrices sobre Concentraciones Horizontales. 3.I Las dificultades financieras de la empresa objeto de adquisición. 3.2 La inexistencia de alternativas menos restrictivas para la competencia. 3.3 La salida inevitable de los activos de la empresa adquirida. 3.4 Las consecuencias del cumplimiento o incumplimiento del test de falta de causalidad entre la operación de concentración y la restricción de la competencia efectiva. 3.5 La reciente praxis comunitaria en torno a la excepción de la empresa en crisis. Asuntos Nynas/ Shell/ Harburg Refinery y Aegean/ Olympic de 2013. 4. El caso particular de la excepción de la división en crisis de una empresa o failing division defence. 4.I Aproximación. 4.2 El asunto Bertelsmann/Kirch/Premiere. 4.3 El asunto Rewe/Meinl. 4.4 El asunto Newscorp/Telepiù. 4.5 La valoración de la failing division defence a la luz de la praxis comunitaria. 5. La excepción de la empresa en meras dificultades o flailing firm defence. 6. La ratio o fundamento de la doctrina de la empresa en crisis. 6.I Planteamiento. 6.2 Nudo. 6.3 Desenlace 7. Bibliografía

\section{Consideraciones preliminares}

Es usual que en las crisis económicas muchos de los operadores del mercado tengan que enfrentarse con graves dificultades. A fin de remediar esta situación, los competidores pueden optar por celebrar operaciones de concentración con empresas que se encuentran en mejores condiciones. De ahí que las autoridades de competencia se vean obligadas a evaluar concentraciones empresariales en las que toman parte empresas con sustanciales inconvenientes financieros (OCDE, 2009, p. I I). A su vez, otras características del mercado pueden indicar la necesidad de que los activos de una empresa en crisis continúen en una determinada industria. Esto acontece generalmente cuando las empresas incumbentes -competidores actualescuentan con una capacidad limitada de producción. En estas circunstancias es preferible consentir la ejecución de una operación de concentración para prevenir cualquier riesgo de salida de dicha empresa, por cuanto que ello puede conllevar una disminución considerable del suministro de los productos en cuestión, y conducir a un ulterior incremento de los precios.

En el sistema europeo de control de concentraciones, las Directrices sobre la evaluación de concentraciones horizontales, publicadas en el DOUE, número C $3 \mathrm{I}$, de 5 de febrero de 2004 -en adelante, Directrices sobre Concentraciones Horizontales-, contienen la excepción de la empresa en crisis o, según sus siglas en inglés, failing company o failing firm defence ${ }^{95}$. Dicha

${ }^{95}$ La excepción de la empresa en crisis o failing firm defence es una doctrina jurisprudencial de origen norteamericano. En esencia, la Corte Suprema estadounidense admitió por vez primera la doctrina de la failing company en la sentencia pronunciada con motivo del asunto Internacional Shoe Co c/FTC de 1930 donde concretaron los presupuestos para su aplicación. Sin embargo, no fue sino hasta 1968, merced a la promulgación de las directrices elaboradas por la División antitrust del Departamento 
excepción faculta a la autoridad antitrust a declarar lícitas o compatibles con el mercado común aquellas operaciones de concentración que, pese a plantear problemas de competencia, son aptas para funcionar como medidas anticrisis de ciertas empresas que, debido a su situación ruinosa, están condenadas a abandonar el mercado -concentraciones de recuperación o saneamiento económico- (MIRANDA SERRANO, 2000, pp. 55-57; FONT GALÁN, MIRANDA SERRANO, PAGADOR LÓPEZ, VELA TORRES, 2004, PP. 463 y ss.; MIRANDA SERRANO \& PÉREZ MOLINA, 20I4, p. 145). Se trata de una doctrina de origen norteamericano que, obviamente, es aplicada por las autoridades europeas de manera excepcional (de ahí, precisamente, que para referirse a ella se hable de «excepción») a aquellos supuestos en los que la empresa objeto de adquisición se encuentra con serias dificultades económicas y financieras. Con fundamento en esta doctrina, las empresas participantes pueden solicitar a la Comisión Europea un trato favorable en relación con el proyecto de concentración en el que participan, alegando que, pese a sus iniciales riesgos competitivos, se revela como la vía más idónea para el aprovechamiento y la conservación de la empresa inmersa en situación de penuria financiera.

Cabe, por tanto, sostener que la excepción de la empresa en crisis flexibiliza la evaluación antitrust de las operaciones de concentración con la finalidad de sanear económicamente a las empresas que atraviesen una delicada situación económica. Al mismo tiempo, esta excepción permite tener en cuenta las ventajas económicas, regionales y sociales que despliegan estas operaciones sobre los trabajadores, los accionistas, los acreedores y la colectividad en general (MIRANDA SERRANO, 2003, p. 186).

El actual momento histórico de crisis económica y social que atraviesa Europa, así como la globalización de los mercados y el aumento de las presiones competitivas entre los operadores, dota de gran actualidad al estudio de la doctrina de la empresa en crisis ${ }^{96}$. A ese cometido destinamos el presente trabajo. Iniciamos con el análisis de los primeros brotes y desarrollos de esta doctrina en el régimen comunitario de control de concentraciones (infra, 2). Posteriormente nos ocupamos de las condiciones que han de concurrir para que resulte aplicable, así como de

de Justicia -en adelante, DOJ-, cuando tales presupuestos adquirieron una sistematización. En la actualidad, los criterios que deben concurrir para su aplicación se fijan en la sección 11 de las Horizontal Merger Guidelines de 2010. Por otra parte, la doctrina de la failing company admite también el supuesto de la adquisición de una división en crisis de una empresa o, en inglés, failing division defence (BRIONES, J., FOLGUERA, J., FONT, A., NAVARRO, E.,1999, pp. 272 y ss.; MIRANDA SERRANO, 2000, pp. 53 a 90; HERRERO SUÁREZ, 2001, pp. 144-148; CALVO CARAVACA \& CARRASCOSA GONZÁLEZ, J., 2006, pp. 224 y 225; KOKKORIS, 2007, pp. 158 y ss.; OCDE, 2009, pp. 22-23 y 175-182; FERNÁNDEZ, 2010, p. 128; U.S. DOJ/FTC, 2010, p. 32; HOVENKAMP, 2011, pp. 600 a 603; LINDSAY \& BERRIDGE, 2012, p. 557, nota 5; SIGNES DE MESA, 2013, p. 177, nota 296).

${ }^{96}$ En cuanto a la crisis financiera, tanto la Comisión Europea como las autoridades nacionales de competencia sostienen que el Derecho de defensa de la competencia, particularmente el control de ayudas públicas y el control de concentraciones, no obstaculizan la recuperación económica, sino que es un instrumento que coadyuva a su solución. Justamente, en el sector bancario, el control de concentraciones previene la formación de estructuras -banking structures- altamente concentradas que a posteriori pueden favorecer a un abuso o, incluso, crear operadores bancarios de grandes dimensiones cuya quiebra pueda afectar de nuevo la estabilidad financiera (conocido como el dilema too big to fail). En este sentido, la Comisión Europea ha reiterado que tales operaciones deben evaluarse en atención de los criterios tanto concurrenciales como extraconcurrenciales del artículo 2 del Reglamento 139/2004. Ello significa que es posible emplear la excepción de la empresa en crisis a las operaciones del sector bancario (KOKKORIS, 2006, p. 494; ARMENGOL I GASULL, 2009, pp. 5-6; RUIZ PERIS, 2010, pp. 785 y ss.; BAUDENBACHER \& BREMER, 2010, pp. 281 a 284; REYNOLDS, MACRORY y SCHOWDHURY, 2011, pp. 1692-1722; GRAVE, 2012, pp. 11-13; SIGNES DE MESA, 2013, pp. 162 y ss.; OCDE, 2009, p. 188). 
las últimas decisiones en las que la Comisión Europea se vale de ella (infra, 3). Seguidamente examinamos los casos particulares de la excepción de la división en crisis y de la denominada flailing firm defence o defensa de la empresa en meras dificultades, que presentan peculiaridades respecto de la doctrina de la excepción de empresa en crisis (infra, 4 y 5). Por último, tratamos de ofrecer cierta luz acerca de las razones de fondo que habilitan a la autoridad antitrust a declarar la legalidad de una operación de concentración con fundamento en la failing firm defence. Como veremos, tal doctrina persigue el saneamiento de una organización productiva, pues se parte de considerar que ello incide positivamente tanto en el desarrollo de una competencia efectiva como en la salvaguarda de los intereses existentes en torno a la empresa en crisis. Por tanto, en la teoría de la empresa en crisis subyacen cuestiones no sólo de competencia, sino también de política industrial, económica y social (infra, 6).

\section{La aplicación de la doctrina de la failing company en el derecho antitrust europeo: origen y evolución histórica}

\section{I Antecedentes históricos de la doctrina de la empresa en crisis en la Unión Europea}

Con anterioridad a la instauración del sistema de control de concentraciones en la Unión Europea, la Comisión tuvo oportunidad de analizar operaciones de concentración en las que participaban empresas con dificultades financieras en el ámbito singular de la industria siderúrgica a la luz del artículo 65 del Tratado Constitutivo de la Comunidad Europea del Carbón y del Acero-CECA-97. En concreto, en la decisión de 27 de junio de 1989 autorizó a varios operadores (y, entre ellos, el Land de Baviera) la constitución de una nueva sociedad denominada Neue Maxhütte Stahlwerke GmbH. A través de dicha sociedad se adquiría el control de las instalaciones y el personal de la empresa Einsenwerk Gesellschaft Maximilianshütte $G m b H$, que había sido declarada en quiebra en 1987. Según la Comisión, un plan de reestructuración con reducciones en la producción, así como el cierre de instalaciones devolvería a la empresa su viabilidad y contribuiría a la reestructuración de la siderurgia comunitaria (COMISIÓN DE LAS COMUNIDADES EUROPEAS, 1990, p. 84; KOKKORIS, 2006, p. 497).

\subsection{La gestación de la failing company bajo el Reglamento 4064/89}

Tras la entrada en vigor del Reglamento 4064/89, publicado en DOUE, número L 395, de 30 de diciembre de 1989, nada impedía que la Comisión Europea insertara en la evaluación antitrust de las concentraciones con dimensión comunitaria criterios de naturaleza extraconcurrencial tales como la eficiencia económica y la situación financiera de las empresas participantes en la operación de reestructuración. Tanto la letra b) del apartado I del artículo 2 como el considerando 13 -actual considerando 23- del Reglamento 4064/89 obligaban a la Comisión a tener en cuenta las ventajas que conllevaba la operación de concentración para el progreso técnico y económico, siempre que fuesen en beneficio de los consumidores. Al mismo tiempo dichas normas exigían a la autoridad antitrust situar el examen concurrencial de las operaciones de concentración dentro los fines perseguidos por la Unión Europea; a saber: la promoción entre los Estados miembros del desarrollo, el empleo, la solidaridad y la cohesión social. En sentido amplio, la doctrina de la empresa en crisis puede ser ponderada como una forma de eficiencia empresarial. Ahora bien, a diferencia de la excepción de la eficiencia económica, no se limita a cuantificar los beneficios que genera la operación de reestructuración sobre los consumidores como el ahorro de costes fijos y variables que impliquen precios más bajos (HERRERO SUÁREZ, 200 la, pp. 1943 y ss.; CALVIÑO, 2003, p. 74; PÉREZ MOLINA, 20I5, pP. 308 y ss.). En principio, las concentraciones de recuperación eliminan los fallos o ineficiencias en la administración de la empresa afectada y suprimen los costes de producción. Asimismo contribuyen a conservar los puestos de trabajo, las inversiones de los accionistas, los ingresos

\footnotetext{
${ }^{97}$ Cabe destacar que el CECA expiró el 23 de julio de 2002.
} 
públicos que genera la empresa para la comunidad en donde desarrolla sus actividades, la posibilidad de llevar a cabo la estrategia de compra y, en particular, se revela como el único medio de supervivencia de la propia empresa en crisis, lo que repercute en la existencia de una dosis suficiente de competencia en un determinado sector económico. De modo que la prohibición de una concentración en la que una de las partes es una empresa en graves dificultades produciría perjuicios socioeconómicos e inconvenientes para el normal desenvolvimiento de la libre competencia. Esto significa que la legitimidad de la admisión de la failing firm defence no había de residenciarse exclusivamente en el artículo la letra b) del apartado I del artículo 2 y el considerando I 3 del Reglamento 4064/89, sino también en el propio sistema de economía social de mercado, que se erige en instrumento para la consecución de fines económicos, regionales e industriales en el marco de la Unión Europea -actual apartado 3 del artículo 3 TUE, publicado en el DOUE, número C 83, de 30 de marzo de 20I0-.

Ahora bien, si es cierto que en la práctica la Comisión Europea siempre fue reacia a incluir la eficiencia económica o cuantitativa en el examen de la conformidad o disconformidad de la operación de concentración con la normativa de control de concentraciones, no menos cierto es al mismo tiempo que esos recelos se acrecentaban considerablemente cuando se trataba de ponderar la excepción de la empresa en crisis, al converger en ella intereses de índole económico, regional, social e industrial. Pese a ello, cabe afirmar que la interpretación de la doctrina de la failing firm defence ha evolucionado sustancialmente desde que vio la luz el Reglamento 4064/89 (OCDE, 1995, pp. 18-19; CALVIÑO, 2003, p. 74; KOKKORIS, 2006, pp. 506-507; BAVASSO \& LINDSAY, 2007, pp. 185 y ss.).

A continuación, analizaremos los casos más importantes de la aplicación de la doctrina de la empresa en crisis bajo la vigencia del Reglamento 4064/89. En particular, pondremos la mirada en los distintos criterios que tanto la Comisión como los tribunales europeos elaboraron para admitir dicha doctrina.

\subsection{El asunto Aérospatiale-Alenia/De Havilland}

La primera referencia a la doctrina de la failing company se encuentra en la decisión de 2 de octubre de 199I, asunto Aérospatiale-Alenia/De Havilland, publicada en DOUE, número L 334, de 5 de diciembre de 199I. En ella se valoró la operación de adquisición por parte de Alenia y Aérospatiale de la empresa De Havilland -división regional de Boeing- (considerando 3I). Las empresas participantes invocaron la excepción de la empresa en crisis, argumentando que si la concentración propuesta no se ejecutaba, De Havilland sería eliminada de la competencia a medio - largo plazo. La Comisión, sin embargo, se limitó a declarar que tal desaparición no era probable, toda vez que De Havilland fabricaba productos de gran calidad y prestigio, sus ventas habían aumentado, los costes de producción se habían reducido y era capaz de incrementar su producción. Además, apreció que, de no ejecutarse la operación y producirse la salida del mercado de De Havilland, las partes no eran los únicos compradores potenciales, puesto que otros operadores mostraron su interés en la adquisición. La Comisión Europea dejaba así abierta la cuestión de si la teoría de la empresa en crisis tenía o no cabida en el Reglamento 4064/89 (ALLENDESALAZAR CORCHO, 1992, p. 79; OCDE, 1996, pp. 93-94; KOKKORIS, 2006, pP. 497-498; CALVO CARAVACA \& CARRASCOSA GONZÁLEZ, 2006, p. 225;BISHOP \& WALKER, 20I0, p. 422; FERNÁNDEZ, 2010, p. I29, nota 6; LINDSAY \& BERRIDGE, 20I2, p. 560; SIGNES DE MESA, 20I3, p. 172, nota 283) ${ }^{98}$.

\footnotetext{
${ }^{98}$ Es importante apuntar que si bien las partes alegaron la excepción de la empresa en crisis y la Comisión no se pronunciara en este sentido en su decisión, el asunto Aérospatiale-Alenia/De Havilland se trataba más bien de un supuesto de la defensa de la división en crisis de una empresa, pues $D e$ Havilland era en realidad una división del grupo Boing (OCDE, 1996, p. 94; KOKKORIS, 2006, p. 498).
} 


\subsubsection{El asunto Kali+Salz/MDK/Treuhand}

En rigor, la primera vez que la Comisión aplicó la excepción de la empresa en crisis fue en la decisión de 14 de diciembre de 1993, asunto Kali+Salz/MDK/Treuhand, publicada en DOUE, número $L$ 186, de 21 de julio de 1994. En dicha operación participaron la empresa $K+S$, que tenía como objeto principal la producción de potasa, sal y productos derivados, y la entidad pública Treuhand, creada para reestructurar las antiguas empresas estatales de la desaparecida República Democrática Alemana, que era la única accionista de la empresa MDK dedicada a la potasa y la sal gema, y que se encontraba inmersa en una fuerte situación de crisis. Esto se debía fundamentalmente a la estructura deficiente de la empresa, a la crisis de ventas por el colapso de los mercados en Europa oriental y a la reducción notable del consumo en el mercado alemán. Las empresas adquirentes $(K+S$ y Treuhand) se proponían convertir a MDK en una empresa en participación. A raíz de esta operación de concentración se originaría un monopolio en el mercado alemán de la potasa de uso agrícola, al alcanzar la nueva empresa en participación una cuota del 98 por ciento en dicho mercado. En principio, esta situación debería haber llevado a la autoridad antitrust a declarar la operación de concentración incompatible con el mercado común, si sólo se hubieran tomado en consideración criterios estrictamente concurrenciales (OCDE, 1996, pP. 92-93; BRIONES et al., 1999, pp. 273 y ss.; MIRANDA SERRANO, 2000, pP. 75 y ss.; HERRERO SUÁREZ, 200 I, pp. I 48 y I49; MIRANDA SERRANO, 2003, pp. 204 y ss.; BACCARO, 2004, PP. 13 a 15; BISHOP \& KOKKORIS, 2006, op. cit., Pp. 498-499; CALVO CARAVACA \& CARRASCOSA GONZÁLEZ, 2006, op. cit., Pp. 225-227; WALKER, 2010, pP. 42I-422; FERNÁNDEZ, 2010, pp. 129 y ss.; ROSENTHAL \& THOMAS, 2010, pp. 200 a 202; JONES \& SUFRIN, 20I I, pp. 943-945; LINDSAY \& BERRIDGE, 20I2, pP. 559-560).

Ahora bien, la Comisión Europea estimó que en dicho caso era aplicable la doctrina de la empresa en crisis y que, a su juicio, la operación era conforme con el apartado 2 del artículo 2 del Reglamento 4064/89, es decir, con el criterio de compatibilidad, puesto que no implicaba un empeoramiento de la estructura competitiva del mercado. En palabras de la Comisión: "puede considerarse que una operación de concentración, que en condiciones normales, crearía o reforzaría una posición dominante de la empresa adquirente en el mercado, no constituye la causa de dicha posición de mercado cuando, aunque se prohibiera la operación de concentración, dicha empresa adquiriría o reforzaría necesariamente su posición dominante en el mercado" (considerando 7I).

La Comisión precisó que, en general, no existe nexo causal entre la operación de concentración y el deterioro de la competencia en el mercado en los casos en que concurren los siguientes presupuestos: a) de no ser por su adquisición, la empresa absorbida estaría obligada a abandonar el mercado a corto plazo; b) la cuota de mercado de la empresa adquirida acrecería a la empresa adquirente en caso de que la primera saliera del mercado; y c) no exista otra alternativa de adquisición menos perjudicial para la competencia(considerando 7I). Al mismo tiempo, advirtió que la falta de vínculo de causalidad entre la operación de concentración y la posición de dominio creada o reforzada únicamente acaecía en casos excepcionales. En circunstancias normales, es decir, cuando ninguna de las empresas partícipes se encontraba en situación de crisis, se presumía que la posición de dominio originaba un deterioro de las condiciones de competencia $y$, en consecuencia, la operación de concentración analizada debía declararse incompatible con el mercado común (considerando 72; OCDE, 1996, p. 91).

En este caso la autoridad comunitaria verificó que no existía una relación causal entre la posición de dominio que se creaba por la nueva empresa en participación y la operación de concentración. Según la Comisión, si se prohibía la concentración, la empresa MDK a causa de su fuerte crisis financiera desaparecía del mercado y $K+S$ absorbería su cuota, reforzando inevitablemente su posición de dominio en el mercado alemán de la potasa de uso agrícola. Asimismo, prestó también atención a otros factores como los efectos negativos que derivarían del abandono de MDK en las regiones del Este de Alemania, que ya eran de por sí estructuralmente débiles. De 
igual forma, tuvo en cuenta que el proyecto de concentración beneficiaba a más trabajadores, mientras que otras compras potenciales tenían un alcance más limitado. En suma, todas estas razones llevaron a la Comisión a decretar la compatibilidad de la concentración con el mercado común, valiéndose para ello de la excepción de la empresa en crisis (considerandos 90 y 95). Y de esta forma se incorporó al ámbito comunitario del control de las concentraciones la doctrina jurisprudencial de origen norteamericano que aquí analizamos ${ }^{99}$.

Ahora bien, esta decisión fue recurrida ante el Tribunal de Justicia de la Unión Europea. En su sentencia de 31 de marzo de 1998, asuntos acumulados C-68/94 y C-30/95 - Francia y otros contra la Comisión, en Recopilación de la Jurisprudencia de 1998, el Tribunal confirmó el fundamento jurídico utilizado por la Comisión para aplicar la excepción de la empresa en crisis. No obstante, en esta sentencia se anuló el dispositivo de la cuestión litigiosa ${ }^{100}$. En opinión del Tribunal, si la operación de concentración no era la causa de la creación o el reforzamiento de una posición de domino que afectaba a la competencia efectiva en el mercado común, ésta debía ser declarada lícita. En caso contrario, la operación tenía que ser juzgada ilícita con el mercado comunitario. A su vez, dicha sentencia ponía de manifiesto que si bien el razonamiento de la Comisión sobre la excepción de la empresa en crisis no concordaba plenamente con la teoría de la failing company norteamericana, este dato no podía ser causa de invalidez de la decisión (considerandos II0II2).

Por otra parte, el Tribunal de la Unión Europea reparó que a fin de consentir la aplicación de la excepción de la empresa en crisis -ex Reglamento 4064/89- no era necesario demostrar que la empresa adquirente asumiría las cuotas de mercado de la empresa objeto de concentración, ante su supuesta desaparición del sector económico relevante (criterio de la absorción de las cuotas de mercado). A juicio del tribunal, los criterios decisivos que permitían activar esta excepción se reducían sólo a dos: $I^{\circ}$ ) que la empresa adquirida fuera forzada a dejar el mercado a corto plazo; y $2^{\circ}$ ) que no existiera otra alternativa que lesionara menos a la competencia. Cumpliéndose ambas exigencias, quedaba claro que la operación de concentración no era la causa del detrimento de las condiciones de la competencia, lo que era conforme con el artículo 2.2 y, por consiguiente, daba luz verde a la declaración de compatibilidad de la operación sin sujeción a condiciones (considerandos II4-II6 y I24).

\subsubsection{El asunto BASF/Eurodiol/Pantochim}

Algún tiempo después, la Comisión acogió por segunda vez la excepción de la failing company en la decisión de II de julio de 200I, asunto BASF/Eurodiol/Pantochim, publicado en DOUE, número $L$ 132, de 15 de mayo de 2002, que constituyó un importante paso hacia adelante en la delimitación de los criterios de aplicación de esta doctrina en Europa. En ella se investigó la operación por la que la empresa química BASF pretendía la compra de las empresas belgas Eurodiol y Pantochim, ambas en procedimientos concursales ante sus tribunales nacionales (considerandos 135-I56; BRIONES, J., FOLGUERA, J., FONT., A., NAVARRO, E., 2005, pp. 337-338; BACCARO, 2004, pp. 16 y 17; KOKKORIS, 2006, pp. 501 y ss.; OCDE, 2009, p. 24; BISHOP \& WALKER, 2010, p. 422; ROSENTHAL \& THOMAS, 2010, PP. 202-203; JONES \& SUFRIN, 20I I, pp. 945-946; LINDSAY \& BERRIDGE, 20I2, op. cit., PP. 560-56I).

\footnotetext{
${ }^{99}$ Posteriormente, la Comisión Europea rechazó la teoría de la empresa en crisis en el asunto SaintGobain/Wacker-Chemie/NOM, publicado en DOUE, número L 247, de 10 de septiembre de1997 y, posteriormente, en el asunto Blokker/Toys "R" Us, publicado en DOUE, número L 316, de 25 de noviembre de 1998 .

${ }^{100}$ Es importante señalar que la anulación de la decisión de la Comisión no obedecía a que la doctrina de la failing company no tuviera cabida en el Reglamento 4064/89. Por el contrario, se fundamentó en que, a juicio del Tribunal, la Comisión no probó suficientemente en su decisión que los vínculos existentes entre las empresas en posición dominante colectiva impedirían el mantenimiento de una competencia efectiva entre los miembros del oligopolio en cuestión.
} 
La Comisión continuó haciendo uso en esta materia de su principal argumento, es decir, que la operación de concentración no se presentase como la causa de la merma de la competencia efectiva. No obstante, matizó que el planteamiento del Tribunal era más amplio que el que ella había empleado en la decisión Kali+Salz/MDK/Treuhand. Argumentó que los criterios del Tribunal no excluían completamente la asunción por terceros competidores de los activos de la empresa en crisis. Y si ocurría esto -precisó la Comisión- los efectos económicos serían similares a los de una adquisición distinta de la empresa en dificultades, lo que revelaría la presencia de varias alternativas a la operación de concentración en cuestión. Por consiguiente, el Ejecutivo comunitario añadió a los dos requisitos concretados por el Tribunal de Justicia uno más, que exigía que «los activos de la empresa objeto de compra inevitablemente desaparecieran del mercado si no se llevara a cabo la operación de concentración». De modo que en este nuevo asunto la Comisión Europea cifró en tres los requisitos necesarios para admitir la excepción de la empresa en crisis: a) que la empresa adquirida fuera obligada a salir del mercado en un futuro próximo en el supuesto de que no fuese adquirida por otra empresa; b) que no existiera otra alternativa de adquisición que afectara menos a la competencia; y c) que los activos objeto de la adquisición salieran inevitablemente del mercado si no fueran absorbidos por otra empresa (considerandos 139 a 142).

Junto a lo anterior, la autoridad antitrust formuló una regla de proporcionalidad o de escala progresiva entre la operación de concentración y su resultado -como una especie de rule of reason en las concentraciones de recuperación-. A su juicio, en cualquier caso, la estructura competitiva ocasionada por la concentración de recuperación debía ser por lo menos no peor a la que se produciría en su ausencia. Esto significa que los efectos de la operación de concentración habían de ser similares o proporcionales a los que se generarían a falta de tal operación (considerando 139-143 y 157-162). Ahora bien, es importante advertir que este análisis comparativo -en la literatura anglosajona se conoce como counterfactual- difiere del examen tradicional que se lleva a cabo al enjuiciar transacciones en las que participan empresas financieramente sanas. En las concentraciones de recuperación, la Comisión Europea tiene particularmente en cuenta la hipotética salida de la empresa que atraviesa una situación económica crítica. De ahí que el examen competitivo de las concentraciones de salvamento sea muy complejo, pues la Comisión estudia varios escenarios. Por un lado, la situación que provocaría la operación de concentración a la luz de criterios meramente concurrenciales. Por otro, las circunstancias que se generarían si ésta no llegara a ejecutarse pero en atención a otros cambios inminentes que aún no hubieran acontecido, como el posible abandono de una empresa en crisis en un determinado sector económico (Directrices sobre Concentraciones Horizontales, apartado 9; KOKKORIS, 2006, p. 494; OCDE, 2009, p. I88; NIELS, G., JENKIS, H., KAVANAGH, 20II, pp. 338-339; ROSENTHAL \& THOMAS, 2010, pp. 202-203)'101.

A la vista de lo que acaba de afirmarse, no puede sorprender que en el caso al que ahora nos referimos el Ejecutivo comunitario procediese a evaluar el cumplimiento de los tres requisitos apuntados. El análisis realizado le llevó a confirmar la concurrencia de la crisis financiera de las empresas belgas Eurodiol y Pantochim y la falta de una alternativa menos dañina para la competencia. En cuanto al nuevo criterio, la Comisión reconoció que, ante la salida de Eurodiol y Pantochim, no se esperaba que BASF absorbiera toda su cuota de mercado, pues las partes no

${ }^{101}$ En este sentido, es importante apuntar que esta regla de proporcionalidad difiere del análisis que lleva a cabo la Comisión para comparar las condiciones competitivas que devienen de la operación de concentración con las condiciones que prevalecerían cuando ésta no se produce. Precisamente, en los casos de las concentraciones de recuperación, la Comisión aprecia los futuros cambios en el mercado, esto es, la salida de una empresa. Por ejemplo, en las concentraciones entre entidades financieras, la Comisión valora si en ausencia de la operación de concentración puede producirse un fallo sistemático -systemic failure- a causa de que el banco en crisis es de gran relevancia en un sector financiero (SIGNES DE MESA, 2013, pp. 17 y 18, nota 300). 
eran los únicos competidores en el mercado, siendo, por tanto, bastante probable que los demás operadores también obtuvieran partes significativas. Pese a ello, la Comisión admitió que los activos de las empresas en serias dificultades dejarían definitivamente el mercado, lo que causaba una disminución sustancial de las condiciones de competencia en perjuicio de los clientes. En la investigación, la Comisión valoró que tras la quiebra de ambas empresas era poco factible que inversores privados compraran sus activos. Ello obedecía principalmente a los elevados costes de producción, a la necesidad de una mano de obra cualificada y a la producción integrada de las plantas.

Seguidamente la autoridad antitrust llevó a cabo un análisis comparativo (counterfactual) de los efectos que dimanaban de la operación notificada y de las consecuencias de su prohibición, es decir, del cierre y la expulsión de los activos del mercado de referencia. En esencia, la Comisión determinó que la expulsión inminente de tales activos originaría una escasez en los productos de referencia, ya que se ofrecían con grandes limitaciones y los competidores no serían capaces de satisfacer la demanda a medio plazo, incluso ante un hipotético incremento de los precios. En consecuencia, la Comisión Europea valoró que en razón de las características del mercado como las limitaciones en la producción y la demanda inelástica, se aumentarían los precios por la salida de los activos de las empresas objeto de compra. Por otra parte, la Comisión apreció que este escenario se evitaría al autorizarse la operación de concentración y, a su vez, la nueva entidad disminuiría sus costes, lo que se traducía en precios más bajos. De ahí que el Ejecutivo comunitario concluyera que el escenario más favorable para los clientes era la autorización de la operación de concentración, lo que le llevó a declarar su compatibilidad con el mercado común con fundamento en la doctrina de la empresa en crisis (apartados 150 y I63).

\section{Los presupuestos de la doctrina de la empresa en crisis en el actual Reglamento 139/2004 y en las Directrices sobre Concentraciones Horizontales}

El vigente Reglamento 139/2004 sobre el control de las concentraciones de empresas, publicado en DOUE, número L 24, de 29 de enero de 2004 -en adelante, Reglamento I39/2004- no contiene una regulación expresa de la excepción de la empresa en crisis. Sin embargo, la autoridad antitrust sí se ha referido a esta materia en las Directrices sobre Concentraciones Horizontales, donde ha recogido los tres requisitos fijados en el asunto BASF/Eurodiol/Pantochim ${ }^{102}$. Las mencionadas Directrices exigen, pues, la concurrencia de tres condiciones para que sea aplicable la excepción que analizamos (apartado 90); a saber: a) que la empresa presuntamente en crisis esté condenada por sus problemas financieros a abandonar el mercado en un futuro próximo; b) que no exista otra posibilidad de compra menos perjudicial para la competencia que la concentración notificada; $y$, por último, c) que de no ser por la concentración, la desaparición de los activos de la empresa en crisis resulte inevitable en el mercado relevante (MIRANDA SERRANO \& PÉREZ MOLINA, 20I4, Pp. I45-I48).

Al tratarse de un supuesto especial en el sistema de control de concentraciones, es natural que la carga de la prueba corresponda a las partes, quienes han de presentar a su debido tiempo la información pertinente para demostrar el cumplimiento del requisito básico de la excepción de la empresa en crisis. Es decir, son ellas quienes han de justificar que la obstaculización significativa de la competencia no deriva de la operación de concentración. En general, las partes deben probar que la empresa objeto de adquisición se encuentra en una situación de fuerte crisis económica y que su adquisición, más que perjudicar el funcionamiento de la libre competencia,

${ }^{102}$ Desde una perspectiva de política de competencia, lo importante no es el medio donde se reconoce y desarrolla la doctrina de la failing company como la ley, las directrices o la jurisprudencia, sino más bien la existencia de unos criterios específicos bajo los cuales se estudien las operaciones de concentración en las que participan empresas en serias dificultades financieras (OCDE, 2009, pp. 21 y 22$)$. 
beneficia el desarrollo de la misma y al interés general, al constituir la vía de recuperación o salvamento de la empresa en crisis menos restrictiva para la competencia (Directrices sobre Concentraciones Horizontales, apartado 89 y 90 ). Veamos, pues cada uno de estos requisitos.

\section{I Las dificultades financieras de la empresa objeto de adquisición}

Inicialmente es preciso que las partes en la operación de concentración manifiesten que la empresa objeto de adquisición está condenada, a causa de su penuria económica y financiera, a abandonar el mercado en un futuro próximo si no es absorbida por la empresa compradora. En tal sentido, la autoridad antitrust no exige que la empresa aparentemente en crisis esté sometida a un procedimiento de concurso en el momento de la notificación. Por el contrario, se requiere que de no efectuarse la operación, la empresa se vería abocada a dicho proceso en un futuro cercano. Por consiguiente, la Comisión Europea entiende que el cierre de la empresa adquirida no ha de ser inmediato, sino que es suficiente que existan evidencias de que dicho escenario sea altamente probable en un periodo corto (BRIONES et al., 1999, p. 272, nota 4; MIRANDA SERRANO, 2000, p. 56, nota 9; FERNÁNDEZ, 2010, p. 133)103.

Ahora bien, el problema que plantea este requisito es la ausencia de una fórmula general que revele el grado de insolvencia para comprobar que la empresa adquirida efectivamente está inmersa en una crisis financiera. Ello obliga a la Comisión a evaluar los problemas económicos de una empresa caso por caso (OCDE, 2009, p. 184) ${ }^{104}$. La doctrina suple este vacío indicando que el nivel de crisis se debe apreciar en función de los riesgos competitivos que suscita la operación de concentración. Así, este primer presupuesto ha de seguir una escala progresiva entre la situación de crisis y el daño competencial. En rigor, es posible sostener que cuanto mayores son los problemas competitivos que provoca una operación de concentración, mayor es la exigencia de que la crisis sea cierta e inminente. Por lo general, es oportuno que las partes aleguen que la empresa afectada atraviesa una crisis sustancial por mor de la cual es imposible que continúe sus actividades por sí sola en el futuro próximo. Con tal propósito, es vital que las partes ofrezcan los balances de cuentas en términos de liquidez, rentabilidad y solvencia de la empresa objeto de compra. Por ejemplo, en las concentraciones entre entidades bancarias, este criterio se cumple mediante la confirmación del banco central de los problemas de insolvencia de la institución en crisis. Estos parámetros o estudios contables han de reflejar que la empresa afectada no es capaz sanearse o reorganizarse de forma rentable si mantiene su independencia en el mercado, habida cuenta de las pérdidas pronunciadas en las ventas, los costes de producción insostenibles, la falta de liquidez y las deudas significativas, etc. Justamente se trataría de un supuesto en el que los accionistas no pueden aportar el capital necesario o, en el caso de lograr un financiamiento de un inversor privado, los costes serían superiores a los que presenta la operación de reestructuración, con lo cual no sería una opción viable a largo plazo. Así pues, esta primera condición supone que la empresa objeto de adquisición no atraviesa una situación transitoria de crisis, sino que sufre un elevado grado de penuria financiera y que de no celebrarse la operación propuesta la empresa sería forzada a cerrar y salir del mercado definitivamente. Por ende, la operación propuesta ha de mostrarse como un medio indispensable para la recuperación de la empresa en crisis dado que el adquirente aporta la experiencia de dirección necesaria y logra un efecto de sinergia económica sustancial a fin de salvaguardar los factores de producción en la industria; ad ex., una reestructuración empresarial que comporta la mejora de

103 Por ejemplo, en la decisión de la Comisión Europea, de 14 de diciembre de 1993, asunto Kali+Salz/MDK/Treuhand, afirmó que el abandono de la empresa afectada no era inminente pero si era altamente probable (considerando 77). Asimismo, en la decisión de 11 de julio de 2001, asunto COMP/M.2314 - BASF/Eurodiol/Pantochim, la Comisión apreció que, si bien las empresas adquiridas fueron declaradas en suspensión preliminar de pago previo a la notificación de la concentración, ello sólo ayudó verificar que el peligro de quiebra era inequívoco (considerando 144).

104 Ello obedece a que las legislaciones de los Estados miembros regulan de distinta manera los procesos de liquidación y de reestructuración de las empresas. 
las instalaciones, el aprovechamiento de la red de distribución existente, la explotación de fábricas y almacenes, la reducción de costes y la creación de una nueva gama de productos (OCDE, 2009, pP. 183-184; FERNÁNDEZ, 2010, p. 184; DAVIS \& COOPER, 2010, PP. 13-14; LINDSAY \& BARRIDGE, 2012, PP. 557-558; SIGNES DE MESA, 20I3, p. I79; HERRERO SUÁREZ, 200lb, PP. 158 y 167).

\subsection{La inexistencia de alternativas menos restrictivas para la competencia}

Las empresas partícipes deben demostrar a su vez que la operación de concentración es el único mecanismo para sanear y conservar la empresa en crisis en el mercado relevante. Este criterio presenta una gran dificultad, pues es fundamental que la autoridad antitrust descarte cualquier otra alternativa de compra ya sea de la totalidad o de una parte sustancial de la empresa adquirida distinta del proyecto de concentración ${ }^{105}$.

La Comisión Europea no solicita a las partes que inicien un proceso formal de licitación previo a la notificación de la concentración. Al contrario, demanda que éstas realicen de buena fe toda posible negociación con competidores ajenos a la operación; ad ex., a través del envío de propuestas de adquisición al mayor número posible de operadores y que posteriormente faciliten su participación en el proceso de negociación. En el análisis de este segundo criterio, el tiempo es un factor muy relevante. Significa esto que la rigidez de su verificación está vinculada con el nivel de crisis que sufre la empresa objeto de adquisición. De modo que el Ejecutivo comunitario evita causar mayores problemas financieros, e incluso, es posible que resuelva en un menor plazo la licitud/ilicitud de la operación de concentración (OCDE, 2009, p. 32; BRIONES et al., 1999, p. 274, nota 8; SIGNES DE MESA, 2013, Pp. 173-174; LINDSAY \& BARRIDGE, 20I2, p. 558; DOJ \& FTC, 20I0, p. 32).

Ahora bien, cuando uno o varios operadores se muestran interesados en adquirir la empresa en graves dificultades, la Comisión Europea procede a confrontar los posibles efectos competitivos tanto de la operación en cuestión como de las compras de terceros. En dichos casos, las partes deben probar que tales ofertas originan mayores riesgos competitivos o que, pese a ser iguales o menores, son económicamente inviables (HERRERO SUÁREZ, 200I, PP. I58-I59; SIGNES DE MESA, 2013, Pp. 179-180). En este sentido, es oportuno argumentar que la empresa adquirente cuenta con unos conocimientos específicos en el mercado, una estructura óptima $y$, en particular, que los beneficios económicos o sinergias notificadas sólo pueden lograrse a través de la celebración de la operación de concentración ${ }^{106}$. No obstante, es importante resaltar que el hecho de que el operador más fuerte del mercado sea el comprador de la empresa en crisis no significa per se que no confluyan otros compradores potenciales en la industria o que sea la mejor solución para la supervivencia de dicha empresa, ad ex., las compañías que operan fuera del mercado de referencia o los competidores de menor dimensión pueden ser una mejor opción de compra en lugar de la operación propuesta (Decisión de la Comisión Europea, de 26 de junio de I997, asunto IV/M.890 - Blokker/Toys "R" Us, considerando II3). En suma, es esencial justificar que la operación de reestructuración se revela como la vía más eficiente a fin de lograr

${ }^{105}$ En el asunto Rewe/Meinl, publicado en DOUE, número L 274, de 23 de octubre de 1999, la Comisión Europea rechazó la failing division defence. En particular, destaco que este requisito es difícil de probar, ya que es necesario poner en evidencia que no existe un comprador potencial alternativo a la empresa compradora.

${ }^{106}$ En el Derecho antitrust norteamericano, el DOJ y la FTC consideran como una oferta alternativa razonable cualquier propuesta de compra por un precio superior al valor de los activos en un proceso de liquidación. De esta manera, las autoridades norteamericanas previenen que los competidores realicen ofertas estratégicas que persigan impedir la autorización de la operación de concentración sobre la base de la teoría de la failing company (U.S. DOJ \& FTC, 2010, p. 32, nota 16). 
la recuperación de la empresa en graves dificultades económicas y el mantenimiento de la libre competencia (FERNÁNDEZ, 2010, pp. 135- I36; HERRERO SUÁREZ, 200 Ib, pP. I45-I46)107.

\subsection{La salida inevitable de los activos de la empresa adquirida}

Como se señaló anteriormente, en el asunto Kali+Salz/MDK/Treuhand, la Comisión Europea estipuló como tercer requisito que la cuota de mercado de la empresa en problemas financieros acaeciera únicamente a la empresa adquirente si la primera abandonaba el mercado de referencia. Dicho presupuesto se cimentaba en que las empresas participantes eran los únicos competidores en el mercado relevante-duopolio- $y$, naturalmente, el comprador absorbía de forma exclusiva la cuota de la empresa absorbida. No obstante, el criterio de la absorción de las cuotas de mercado carece de importancia cuando son varios los competidores en el mercado relevante. Por tal motivo, la Comisión fijó como última condición en el asunto BASF/Eurodiol/Pantochim que, de no mediar la operación de concentración, la empresa en dificultades saldría irreversiblemente del mercado $y$, por consiguiente se perderían sus activos tangibles e intangibles. La Comisión exige así un alto grado de certeza en la neutralidad del proyecto de concentración con el normal desarrollo de la libre competencia (considerandos I50 y $|5|)^{108}$.

En concreto, la autoridad antitrust analiza cuál será el futuro de los activos (ad ex., maquinaría, línea de producción, marcas, fábricas, redes de distribución, entre otras) en el supuesto hipotético- que la empresa en crisis sea liquidada después de su quiebra. En consecuencia, pese a que las partes logren acreditar la concurrencia de los dos criterios anteriores, es decir, que la empresa atraviesa una crisis sustancial y que la operación de concentración se revela como una alternativa idónea al menos en el proceso de venta, es probable que tras su liquidación existan terceros que asuman tales activos (OCDE, 2009, p. I86; ROSENTHAL \& THOMAS, 20I0, pP. 204-205; FERNÁNDEZ, 2010, pp. I36-I37; REYNOLDS, N. et al., 20II, p. I708; LINDSAY \& BERRIDGE, 20I2, Pp. 565-567; SIGNES DE MESA, 20I3, p. I8I). En el asunto JCI/FIAMM, publicado en DOUE, número C 24I, de 9 de octubre de 2009, si bien el Ejecutivo comunitario autorizó la operación de concentración, denegó la excepción de la empresa en crisis por no concurrir este tercer presupuesto. Según la Comisión, las partes no demostraron que los activos de producción de la empresa FIAMM dejarían definitivamente el mercado en ausencia de la operación de concentración. Antes bien, confirmó que los distintos activos de la empresa afectada podían ser adquiridos por productores más pequeños en el proceso de liquidación. Por ende, concluyó que al efectuarse dicho proceso los activos de la empresa en crisis se integrarían de nuevo en el mercado a corto plazo, lo que constituía un deterioro de la competencia menor en comparación con la operación en cuestión (considerandos 8 a II) ${ }^{109}$.

\footnotetext{
${ }^{107}$ En el supuesto de una concentración de recuperación entre entidades bancarias con elevadas cuotas de mercado es posible que, en el análisis de este criterio, los Estados miembros pueden ofrecer como alternativa una ayuda pública. En tal caso, la autoridad puede declarar que la ayuda pública es una mejor alternativa. En efecto, las medidas públicas se limitan en el tiempo y quien los recibe está obligado a su devolución, mientras que las operaciones de concentración consisten en una adquisición de control duradera mediante la que se constituye una entidad económica permanente. Sobre este segundo requisito (SIGNES DE MESA, 2013, pp. 180, nota 300).

${ }^{108}$ Precisamente, en el asunto BASF/Eurodiol/Pantochim, la Comisión verificó que los activos de Eurodiol y Pantochim dejarían definitivamente el mercado, pues tras su cierre era poco probable que un tercero comprara sus instalaciones a causa de los elevados costes de producción (considerando 151).

${ }^{109}$ No obstante, en el asunto $B A S F /$ Eurodiol/Pantochim, la Comisión apreció que no era probable que un tercero comprara los activos específicos de las empresas objeto de compra tras su quiebra, dado que, entre otras cuestiones, las instalaciones sólo funcionaban de forma rentable en conjunto y los costes de operación eran elevados. Por ello, determinó que los activos de las empresas adquiridas saldrían inevitablemente del mercado de referencia (considerandos 151 a 156).
} 
En suma, cabe concluir que el examen de este criterio es muy complejo. En particular, si tenemos en cuenta que, desde una perspectiva antitrust, es preferible que los activos sean divididos como unidades independientes entre distintos compradores en lugar de que permanezcan en manos de un solo competidor. A nuestro juicio, el éxito de una defensa basada en la failing company está estrechamente relacionado con las ventajas económicas o eficiencias que resultan de la operación de concentración. Las partes deben probar que las adquisiciones parciales provenientes de la liquidación no alcanzan los beneficios económicos que emanan de la operación notificada o, más aún, que la prohibición de la concentración perjudica los intereses de los consumidores y usuarios. Esto ocurre cuando los activos de producción poseen un mayor valor de forma unitaria, como las plantas que utilizan un proceso de fabricación altamente integrado. Además, en el caso que no exista un exceso de producción en el mercado, la expulsión de los activos disminuiría el suministro de los productos e incrementaría los precios. Por tanto, la operación de reestructuración ha de consentirse con la normativa de control de concentración siempre que la liquidación se vislumbre con un mayor coste o como económicamente ineficiente (FERNÁNDEZ, 2010, p. 137; OCDE, 2009, pP. 20 y I84; KOKKORIS, 2006, pp. 498- 502; SIGNES DE MESA, 20I3, PP. I78-I79; DAVIS \& COOPER, 20I0, p. I5; BISHOP \& WALKER, 2010, p. 42I; LINDSAY \& BERRIDGE, 20I2, p. 559; Decisión de la Comisión Europea, de II de julio de 200I, asunto COMP/M.23 I4 - BASF/Eurodiol/Pantochim, considerandos I57 a I62) 110.

\subsection{Las consecuencias del cumplimiento o incumplimiento del test de falta de causalidad entre la operación de concentración y la restricción de la competencia efectiva}

Una vez que la Comisión Europea ha delimitado los riesgos competitivos de la operación de concentración a la luz de criterios meramente concurrenciales -como la presencia de efectos unilaterales o coordinados en el caso de las concentraciones horizontales-, lleva a cabo el test de falta causalidad entre la operación de concentración y dichos riegos (Directrices sobre Concentraciones Horizontales, considerando I2) 11 . En general, dicho test puede dividirse en dos etapas o fases. En la primera, la Comisión valora la situación financiera de las empresas participantes, pero en razón de las condiciones de competencia que prevalecen en el momento de la notificación del proyecto de concentración. En esencia, verifica si la empresa objeto de adquisición se encuentra inmersa en una crisis económica. Con tal propósito analiza la contabilidad de dicha empresa y, especialmente, tiene en cuenta si sufre pérdidas sustanciales y pronunciadas, así como la incapacidad de hacer frente a sus obligaciones. Después que la Comisión Europea compruebe que la empresa atraviesa una crisis económica, analiza el proceso de venta efectuado por las partes. En especial, la autoridad antitrust requiere que las partes expongan con qué operadores negociaron y por qué fracasaron dichas negociaciones. Ahora bien, en caso de que la Comisión entienda que existen otras compras potenciales, determina cuáles son sus consecuencias competitivas $y$, posteriormente, las compara con los efectos

${ }^{110}$ En este sentido, un sector de la doctrina indica que puede comprobarse que una empresa está inmersa en una crisis cuando el valor de la liquidación es mayor que el valor de continuar en el mercado y, a tal efecto, sería oportuno analizar las sinergias que devienen de la operación de concentración. Sobre estas posturas. Sin embargo, HERRERO SUÁREZ (2001) apunta que la liquidación no puede considerarse como crisis (pp. 158-159), postura que no compartimos como se ha expuesto anteriormente.

${ }^{111}$ Es importante subrayar que en el sistema europeo de control de concentraciones existe un reconocimiento expreso de la doctrina de la empresa en crisis y, de esta manera, faculta a la autoridad antitrust a aplicar el que denominamos test de ausencia de causalidad. Mientras que las legislaciones que no reconocen ésta doctrina utilizan el test de causalidad tradicional (traditional causality test), es decir, valoran la operación de concentración exclusivamente con el criterio sustantivo que contemplen sus ordenamientos. En este último caso, la evaluación de licitud/ilicitud es más compleja, costosa y, además, conduce a resultados menos predecibles. Sin embargo, el informe de la OCDE de 2009 apunta que las conclusiones de uno u otro examen pueden ser similares pero que la admisión de esta teoría norteamericana beneficia la seguridad jurídica de las partes (OCDE, 2009, p. 12). 
nocivos derivados de la concentración. Finalmente, en la segunda etapa o fase, la instancia comunitaria realiza una investigación hipotética de las consecuencias que acaecerían en ausencia de la operación de concentración. Así, estima cuáles serían las condiciones que suscitarían el cierre y la liquidación de la empresa en crisis -counterfactual scenario-. Con tal fin sopesa si la liquidación de los activos de la empresa entre varios compradores es viable o no. Esta última fase es decisiva para la admisión de la defensa de la empresa en crisis, puesto que en función de sus resultados la Comisión concluye si la operación de reestructuración es o no la medida más efectiva para sanear y conservar la explotación unitaria de los activos de la empresa en crisis (OCDE, 2009, p. 183).

Cuando la Comisión Europea confirme el cumplimiento del test de falta de causalidad, es decir, la concurrencia acumulativa de los tres criterios anteriormente apuntados, declara que la operación de concentración es conforme con el apartado 2 del artículo 2 del Reglamento 139/2004, pues la operación no es la causa de la creación o el reforzamiento del poder de mercado de la nueva entidad. Además, con ello se confirma que a falta de la operación de concentración, los activos de la empresa en crisis abandonarían el mercado, lo que produciría un resultado similar o más nocivo para la libre competencia, ad ex., si la empresa adquirida es de gran importancia para el desarrollo y la innovación de un sector económico (KOKKORIS, 2006, p. 496). En cambio, en el supuesto de que la operación de concentración no supere dicho test, la Comisión reconoce que ésta es la causa directa de la obstaculización significativa de la competencia en el mercado de referencia y, por ende, la mejor opción es que la operación no llegue a celebrarse, a menos que se modifique el proyecto inicial. Ello ocurre principalmente cuando: a) la empresa objeto de adquisición no está en crisis y, en consecuencia, la operación de concentración responde a una estrategia empresarial, ad ex., cuando los órganos de administración decidan que la empresa objeto de compra no logró las expectativas de crecimiento (Decisión de la Comisión Europea, de 27 de mayo de 1998, asunto IV/M.1993 Bertelsmann/Kirch/Premiere, considerando 72; Decisión de la Comisión, de 3 de febrero de 1999, asunto IV/M.I22I - Rewe/Meinl, considerando 66); y, b) pese a que la empresa sufre una grave crisis, existen otros competidores actuales o potenciales que pueden comprar tal empresa, ya sea como una organización operativa o tras su efectiva liquidación, lo que provoca un perjuicio menor para la competencia (Decisión de la Comisión Europea, de 4 de diciembre de 1996, asunto IV/M.774 - Saint-Gobain/Wacker-Chemie/NOM, considerando 249 y ss.; Decisión de la Comisión Europea, de 26 de junio de 1997, asunto IV/M.890 - Blokker/Toys "R" Us, considerando II3). Por tanto, aunque la operación no supere el test de ausencia de causalidad es posible que se autorice con ciertas condiciones, salvo que se trate de una lesión grave de la competencia, en donde procederá emitir una declaración de incompatibilidad (OCDE, 2009,, pp.186-187).

\subsection{La reciente praxis comunitaria en torno a la excepción de la empresa en crisis. Asuntos Nynas/Shell/Harburg Refinery y Aegean/Olympic de 2013}

Como apuntamos al inicio del presente capítulo, la doctrina de la empresa en crisis suscita especial importancia en momentos de crisis económica. En la actual coyuntura que atraviesa el mercado único europeo, la Comisión ha recurrido a la doctrina de la empresa en crisis a fin de mitigar los riesgos competitivos que planteaban los recientes asuntos Nynas/Shell/Harburg Refinery y Aegean/Olympic (ASSIMAKIS \& JERAM, 2014, PP. 605 y ss.; FOUNTOUKAKOS \& GEARY, 20I3, pp. 2 y ss.).

En la decisión de 2 de septiembre de 2013, asunto Nynas/Shell/Harburg Refinery, publicado en DOUE, número C 368 , de 17 de septiembre de 2014, la autoridad antitrust evaluó la adquisición de los activos de la refinería ubicada en Harburg propiedad de Shell por parte del operador sueco Nynas AB (considerandos 23-38). En la primera fase del procedimiento, la Comisión precisó que la nueva entidad se convertiría en el único productor de aceites de base nafténica, es decir, que la operación creaba un monopolio. Posteriormente, en la segunda fase de la investigación, la 
Comisión consideró que la empresa en crisis, la refinería Harburg propiedad de Shell, saldría del mercado de forma inevitable, lo que reduciría drásticamente la producción de aceites de base nafténica y los consumidores pagarían precios más altos, pues los productos debían ser importados al mercado europeo. De modo que la Comisión verificó que la operación no era la causa del deterioro de la competencia, puesto que no existía otra alternativa menos dañina y, a su vez, la operación generaba eficiencias mediante la reducción significativa de los costes variables, lo que se trasladaría a los consumidores. Finalmente, la Comisión concluyó que la operación no generaba problemas de competencia y, por consiguiente, la declaró compatible con el mercado único europeo (COMISIÓN EUROPEA, 20I3, PP. I-3).

Un mes después, la Comisión nuevamente utilizó la doctrina de la failing firm defence en la decisión de 9 de octubre de 2013, asunto Aegean/Olympic II, publicada en DOUE, número C 25, de 24 de enero de 2015. La operación consistía en la adquisición total de Olympic Air por su rival Aegean Airlines, ambas aerolíneas griegas (considerandos 67 y 68). Preliminarmente, la Comisión indicó que las partes coincidían en siete rutas de las cuales sólo cinco se ofrecían por las mismas. Además, señaló que el mayor competidor de tales empresas, Cyprus Airways, no ejercería una presión competitiva importante y que el mercado tenía altas barreras de entrada por lo que no se esperaba el ingreso de nuevos competidores. A raíz de estas circunstancias, la Comisión temía que la operación diera lugar a un monopolio o a una posición fuerte en el sector en cuestión. Sin embargo, en el examen de los factores compensatorios, la Comisión apreció que Olympic Air saldría del mercado en un futuro próximo debido a la particular situación de crisis en Grecia la cual propició una caída de un $26 \%$ en la demanda del transporte nacional aéreo y un menoscabo significativo de la situación financiera de dicho operador. El Ejecutivo comunitario afirmó que, en ausencia de la operación de concentración, Aegean Airlines se consolidaría como el único proveedor de servicios a nivel nacional e inevitablemente adquiriría las cuotas de la primera. Además, corroboró que Aegean Airlines era el único comprador creíble y, en consecuencia, que de no autorizarse la operación de concentración los activos de Olympic abandonarían el mercado de referencia. Lo anterior llevó a la Comisión a concluir que la operación propuesta no era la causa del deterioro de las condiciones de competencia, toda vez que dicho escenario se hubiera formado con independencia de su celebración, por lo que aprobó la operación sin compromisos (COMISIÓN EUROPEA, 20I3b, PP. I-2).

Estos dos casos permiten sostener que la teoría de la failing company se muestra como un instrumento que permite flexibilizar o relajar el criterio sustantivo de la obstaculización significativa de la competencia. En ambos la Comisión concluyó que las operaciones de reestructuración no eran la causa del deterioro de la competencia. En su fundamento, la Comisión estimó los perjuicios que se ocasionarían de una posible prohibición para los consumidores, la difícil situación económica en la que operaban las empresas participantes, la crisis en Grecia y la merma en el progreso de la comunidad en general. En definitiva, cabe afirmar que sin la mediación de la excepción de la empresa en crisis la Comisión no hubiera declarado su compatibilidad con el mercado único europeo, pese a la situación financiera de las empresas y a las características de los sectores relevantes.

\section{El caso particular de la excepción de la división en crisis de una empresa o failing division defence}

\section{I Aproximación}

La excepción de la división en crisis de una empresa hace referencia a las concentraciones de recuperación o salvamento que tienen por objeto solo una división o parte de una empresa y no la totalidad de la entidad u organización empresarial (ROSENTHAL \& THOMAS, 2010, p. 200). En estos casos la obligación de probar la ausencia de nexo causal entre la operación de adquisición de una división y el daño a la competencia corresponde siempre, como es natural, a las empresas participantes. 
Las Directrices sobre Concentraciones Horizontales no fijan unos criterios específicos para la aplicación de la excepción de la división en crisis de una empresa. Empero, en la práctica comunitaria los criterios de la excepción general de la empresa en crisis también han sido utilizados para analizar la absorción de una división en crisis o failing division defence (OCDE, 2009 , pp. 23 y 180$)^{1 / 2}$. Es cierto, no obstante, que tales criterios se han venido aplicando con mayor rigidez, lo que obedece a que las autoridades antitrust consideran que en las concentraciones en las que se adquiere sólo la división de una empresa aparentemente en dificultades persisten más posibilidades de que sean alterados los balances contables y financieros a fin de que las alegaciones de las partes se ajusten al test de falta de causalidad entre la operación de concentración y el daño ocasionado al orden concurrencial.

En efecto, las autoridades de competencia han estudiado con mayor cautela si la operación responde a una crisis económica real o simplemente a una decisión de gestión empresarial. Usualmente, esto acontece cuando los activos de la parte de un negocio no abandonan inmediatamente el mercado de referencia puesto que la matriz tiene motivos estratégicos para mantener activa la división, incluso ante graves pérdidas iniciales o pese a la declaración de prohibición de la operación de concentración. Por consiguiente, es de esperar que en las operaciones en las que tome parte una división en crisis resulte altamente complicado demostrar la ausencia de nexo causal entre tal operación y las consecuencias perniciosas para la competencia (OCDE, 2009, pp. 12, 25 y I86).

En los apartados siguientes, estudiaremos los casos más relevantes sobre la failing division defence en la práctica comunitaria.

\subsection{El asunto Bertelsmann/Kirch/Premiere}

La Comisión Europea evaluó la excepción de la división en crisis por vez primera en la decisión de 27 de mayo de 1998, asunto Bertelsmann/Kirch/Premiere, publicada en DOUE, número L 53, de 27 de febrero de 1999 (KOKKORIS, 2006, pP. 500-50I; CAPOBIANCO, 20I0, p. 2I). La transacción consistía básicamente en la adquisición del control conjunto de las empresas Premiere, BetaDigital y BetaResearch por CLT-UFA y Taurus. Dicha adquisición creaba un monopolio en el mercado de la televisión de pago y otro en el mercado de servicios técnicos de la televisión de pago en Alemania. En cuanto al primer mercado, las partes alegaron que la absorción por Premiere de DFI no era la cusa de la situación monopolística, ya que esta última se encontraba en una situación de crisis.

En su investigación la Comisión constató que la operación de concentración no daba lugar a la retirada del mercado de una empresa en su totalidad, sino que sólo se producía dicho efecto en relación con una concreta división, puesto que $D F I$ sólo representaba una parte de las actividades de su matriz Kirch. Esta constatación le llevó a advertir que en este asunto estábamos, en rigor, ante un caso de failing division defence, en el que los criterios de falta de causalidad habían de aplicarse de forma más estricta. Y es que, de no ser así, toda concentración empresarial que conllevase la venta de una división supuestamente no rentable podría justificarse bajo la normativa de control de concentraciones mediante la mera declaración del vendedor de que, de no autorizarse la operación, la división dejaría el mercado de referencia.

La Comisión realizó el examen de falta de causalidad a la luz de los criterios fijados en el asunto Kali+Salz/MDK/Treuhand. Obviamente, el criterio de la absorción de las cuotas de mercado era relevante, pues la operación se efectuaba en un duopolio. Según la Comisión, DFI no atravesaba

112 En cambio, las Horizontal Merger Guidelines norteamericanas de 2010 incluyen expresamente la failing division defence y sus requisitos (U.S. DOJ \& FTC, 2010, p. 32; HOVENKAMP, 2011, pp. 602603). 
una crisis financiera que le forzara a salir del mercado. Más bien la operación respondía a una decisión de gestión por la que se abandonaba una actividad comercial que, según los órganos de administración, no superaba las expectativas de crecimiento en el mercado. Asimismo, comprobó que si DFI era expulsada del sector, otros operadores potenciales ingresarían en el mercado de la televisión de pago y competirían con Premiere. Además, estimó que si la empresa hubiera negociado la venta de la división con distintos competidores era previsible que tales negociaciones se hubieran concluido de manera exitosa.

Todo lo anterior llevó a la autoridad antitrust a rechazar la aplicación de la excepción de la división en crisis, sobre la base de que las partes no llegaron a probar la ausencia de causalidad entre la operación de concentración y la situación monopolística. De ahí que terminara reconociendo que la operación de concentración era la causa de la producción de efectos negativos sobre la competencia (la creación de una posición dominante) y, por tanto, que la operación de concentración analizada tenía que ser declarada incompatible con el mercado común.

\subsection{El asunto Rewe/Meinl}

La Comisión Europea también ponderó la excepción de la división en crisis en la decisión de 3 de febrero de 1999, asunto Rewe/Meinl, publicada en DOUE, número L 274, de 23 de octubre de 199 (BACCARO, 2004, Pp. I5-16; KOKKORIS, 2006, p. 50I). En este caso el proyecto de concentración suponía la adquisición de todo el capital social de Meinl por parte de la empresa Rewe. Y como consecuencia de la operación se creaba una posición dominante en el mercado austriaco de alimentación al por menor. Las partes defendían que Meinl adolecía de grandes desventajas competitivas frente a otros competidores. A juicio de la Comisión, la operación sólo afectaba a parte de las actividades comerciales y a 7 filiales del grupo Meinl, por lo que debía catalogarse como un caso singular de failing division defence.

Al igual que en la decisión anterior, la Comisión se valió también en este asunto de los criterios utilizados en el caso Kali+Salz/MDK/Treuhand, aplicados de manera minuciosa. Sostuvo que si bien la situación financiera de la empresa se había deteriorado, las partes no aportaron pruebas que esclarecieran que Meinl llegaría a ser insolvente. Por ello presumió que la operación propuesta se basaba en una decisión estratégica de su dirección. Al mismo tiempo, verificó que ante una hipotética salida de los activos objeto de adquisición, las cuotas de mercado no pasarían a Rewe. Además, puso de manifestó que las partes no indicaron con qué compradores potenciales negociaron ni por qué fracasaron las negociaciones. De ahí que, al igual que en el asunto anteriormente aludido, tampoco en este caso la Comisión aceptara aplicar la excepción de la división en crisis. A su juicio, la operación de concentración era la causa de la posición dominante en el mercado de alimentación al por menor de Austria; aunque finalmente terminó autorizando la concentración pero con sujeción a determinadas condiciones (KOKKORIS, 2006, PP. 499. 500).

\subsection{El asunto Newscorp/Telepiù}

Finalmente, hemos de mencionar la decisión de la Comisión Europea, de 24 de abril de 2003, asunto Newscorp/Telepiù, publicado en DOUE, número L II0, de 16 de abril de 2004 (CAFFARRA \& COSCELLI, 2003, PP. 625-627; MENDES PEREIRA, 2003, PP. 30 y ss.; BACCARO, 2003, Pp. 8-II; KOKKORIS, 2006, Pp. 504 a 505; LINDSAY \& BERRIDGE, 20I2, PP. 562-563). Esta operación comprendía el control exclusivo de la división Stream por parte de una de sus sociedades matrices, Newscorp, que al mismo tiempo adquiría la empresa Telepiù. En el análisis de los efectos competitivos, la Comisión sostuvo que la concentración originaba un monopolio en el mercado italiano de la televisión de pago y una posición de cuasimonopolio en los mercados de compra de contenido, puesto que las empresas objeto de concentración eran los únicos operadores en dichos mercados. En el pliego de cargos, Newscorp argumentaba que 
Stream era una empresa en quiebra y que saldría del mercado. Así pues, se planteaba si era posible que una matriz financieramente sana asumiera los activos de una de sus filiales en aparente crisis.

La Comisión manifestó en este asunto que en estos supuestos la importancia de probar los criterios de ausencia de causalidad era mayor que en las transacciones donde el comprador no contralaba previamente la división, toda vez que la matriz adquirente podía tener razones estratégicas para mantener activa su división incluso cuando se prohibiera la operación de concentración (considerando 212; KORAH, 2007, p. 4I7; BAVASSO \& LINDSAY, 2007, pp. 188 189). En el examen del test de falta de causalidad, la Comisión consideró que la operación respondía a una decisión de gestión y no a una concentración de salvamento. Además, sostuvo que, pese a una salida hipotética de Stream, la sociedad matriz no sería forzada a dejar el mercado, ya que la operación sólo abarcaba parte de sus actividades económicas ${ }^{113}$.

En cuanto a la existencia de otra alternativa menos perjudicial, la Comisión corroboró que las partes nunca ofrecieron públicamente la venta de Stream, por lo que no superaron este presupuesto. En referencia al último criterio, esto es, la salida de activos de la división en crisis del mercado, valoró que, en atención al incumplimiento de la primera y segunda condición, no era indispensable adoptar una decisión final sobre la presencia o no de este tercer requisito. Al igual que en el caso anterior, la Comisión terminó declarando que las partes no probaron los criterios de ausencia de nexo causal, aunque finalmente autorizó también la concentración pero con condiciones.

\subsection{La valoración de la failing division defence a la luz de la praxis comunitaria}

A la vista de las anteriores decisiones, es posible deducir que la failing division defence se admitirá en menor medida que la failing company, dado que la Comisión efectúa el examen de falta de causalidad con mayor severidad. $Y$ ello sobre la base de considerar que tales transacciones no necesariamente persiguen el rescate de una división en graves dificultades, sino que pueden responder a motivos estratégicos tales como el abandono de una actividad que no logra los objetivos trazados por los órganos de administración. De ahí que la doctrina sostenga que las concentraciones de recuperación de una división han de revelarse como instrumentos que coadyuven a la prevención de situaciones de crisis de sus matrices que les obliguen a abandonar el mercado de referencia (OCDE, 2012, p. 12; BAVASSO \& LINDSAY, 2007, p. I88; LINDSAY \& BERRIDGE, 20I2, p. 558, nota I2).

\section{La excepción de la empresa en meras dificultades o flailing firm defence}

Cuando las partes fracasan en demostrar la excepción de la empresa en crisis o la defensa de una división en crisis, es posible el recurso a lo que se denomina en la literatura anglosajona como flailing firm defence o excepción de la empresa débil o en meras dificultades.

Como se desprende de su propio nombre, la teoría de la flailing firm defence no abarca las operaciones de concentración en las que la empresa objeto de adquisición -o una de sus divisiones- se encuentran en una profunda crisis que le obliga a salir del mercado a corto plazo. Antes bien, esta teoría hace referencia a las transacciones en las que el operador es

\footnotetext{
${ }^{113}$ La doctrina señala que esta interpretación de la Comisión entraña que para el éxito de una defensa de la división en crisis es necesario que la concentración evite que la matriz se convierta en insolvente; en otras palabras, que la venta de la división permita prevenir que la crisis se propague a toda la matriz y la fuerce a dejar el mercado (BAVASSO \& LINDSAY, 2007, p. 188; LINDSAY \& BERRIDGE, 2012, p. 558).
} 
financieramente débil, por carecer de los recursos financieros necesarios para competir de forma eficiente en el futuro.

Por tanto, las limitaciones de la empresa objeto de adquisición en el momento de celebrarse la operación de concentración son factores a ponderar en el análisis antitrust, pues de ello depende que la empresa débil o en meras dificultades ejerza a largo plazo su función competitiva, esto es, pueda presionar o restringir el comportamiento del resto de competidores en un determinado sector económico. Debe, en suma, de averiguarse si el proyecto de concentración objeto de análisis se presenta o no como un medio que fomenta el normal funcionamiento de la libre competencia en una industria (KOKKORIS, 2006, p. 509; OCDE, 2009, pp. 25 y 180).

En el régimen europeo de control de concentraciones, la doctrina apunta como caso singular de la flailing firm defence el asunto Newscorp/Telepiù (CAFFARRA \& COSCELLI, 2003, p. 627; BACCARO, 2004, pp. 22 y 23; KORAH, 2007, p. 4I7; OCDE, 2009, p. 25; CAPOBIANCO, 2010, p. 2I). Pese a que la Comisión Europea no aceptó la excepción de la división en crisis, valoró la situación financiera de las partes, el menoscabo a los intereses de los consumidores y las características del mercado de referencia a fin de declarar su conformidad con el mercado único. En concreto, la Comisión declaró que si bien las partes no acreditaron la ausencia de nexo causal entre la concentración y el efecto sobre la competencia, el riesgo de la salida de la división Stream era un elemento a tener en cuenta en la evaluación de la concentración. Al mismo tiempo consideró que la aprobación del proyecto de concentración -aunque con sujeción a condiciones- se presentaba como la solución más beneficiosa para los consumidores; desde luego mucho más favorable que el desasosiego originado por el posible cierre de Stream (considerando 22I).

La autoridad de competencia apreció que el mercado de la televisión de pago tanto en Italia como en Europa se identificaban por los altos niveles de costes que debían contraer los operadores. Asimismo, advirtió que en Italia el nivel de ingreso y expansión de los competidores era inferior que al de otros países comunitarios y, en consecuencia, la base de clientes y los ingresos para amortizar los costes eran más restringidos. Estas circunstancias provocaron que Telepiù y Stream incurrieran en graves pérdidas, lo cual repercutió en su estabilidad financiera (considerandos 82 a 88 ).

Dado que la operación de concentración creaba un monopolio, la Comisión aceptó un paquete de compromisos que perseguían facilitar el acceso de nuevos competidores y el esparcimiento de los actuales (operadores de cable pequeños). Así fue como la autoridad comunitaria trató de reducir las barreras de entrada y expansión lo máximo posible, a fin de que estos competidores contrarrestaran el comportamiento de la nueva entidad en la industria italiana de la televisión de pago. Con ello se mitigaba cualquier posición de dominio, y al mismo tiempo se ayudaba al normal desenvolvimiento de una competencia efectiva.

Como apunta la doctrina, la Comisión realizó en este caso un análisis comparativo (counterfactual) entre el escenario que formaba la operación de concentración con el contexto que devenía de los compromisos asumidos por las partes y la hipotética salida de Stream debido a su debilidad financiera. En este último caso, la amenaza de la expulsión de Stream originaba que sólo Telepiù subsistiera en el mercado y adquiriera una situación económica privilegiada que le facultaba alterar las condiciones de la competencia -especialmente, los precios y la variedad de los productos-. De ahí que el proyecto de concentración modificado con los compromisos se mostrara más beneficioso para los consumidores -en sentido amplio se trataría de eficiencias que dimanaban de la transacción que reflejó el counterfactual- (considerandos 226 y ss.; CAFFARRA \& COSCELLI, A., 2003, PP. 626 y 627; BACCARO, 2004, PP. 22-23; BAVASSO \& LINDSAY, 2007, p. I89; LINDSAY, \& BERRIDGE, 20I2, p. 563). 
A la postre, podemos afirmar que la flailing firm defence no implica una flexibilización de los criterios de causalidad ni libera a las partes de la carga de prueba (OCDE, 2009, p. I80; SIGNES DE MESA, 2013, p. 179). Son las empresas participantes las que siempre han de demostrar que la operación notificada no obstaculiza significativamente la competencia ni lesiona el bienestar de los consumidores y usuarios. Por consiguiente, cuanto mayor sea el daño previsible para los consumidores y la competencia a falta de la operación de concentración, más posibilidades tienen las partes de lograr una defensa con fundamento en la doctrina de la empresa débil o en meras dificultades.

Por último, es importante destacar que tanto la excepción general de la empresa en crisis como la particular de la división en crisis cuentan con unos criterios muy rigurosos. Esto explica que hasta la fecha hayan sido pocos los supuestos que han superado el test de causalidad. Por ello no parece difícil vislumbrar que la flailing firm defence tendrá éxito en menor medida, presentándose como el último escalafón o mecanismo al que las partes pueden acudir con el fin de obtener la autorización de la operación de concentración (OCDE, 2009, p. 21 ).

\section{La ratio o fundamento de la doctrina de la empresa en crisis}

\section{I. Planteamiento}

A lo largo de la evolución de la doctrina de la failing company se han invocado distintas argumentaciones que pretenden justificar su aplicación en el ámbito particular del control de las concentraciones de empresas. Se trata de las siguientes:

$\left.I^{a}\right)$ La primera es de política industrial y se apoya en los beneficios económicos o sinergias que emanan de las concentraciones en las que toma parte una empresa en crisis. Desde este punto de vista, se sostiene que las concentraciones de saneamiento económico son los medios más eficientes con vistas a lograr la conservación y utilización de los activos afectados en un determinado sector económico.

$2^{a}$ ) La segunda es de política social y se basa en la protección de los intereses de distintos sujetos o sectores que pueden ser perjudicados por el cierre de la empresa inmersa en una fuerte situación de crisis; a saber: los trabajadores perderían sus puestos de trabajo, los accionistas no recuperarían sus inversiones, los acreedores no recobrarían sus préstamos e intereses $y$, en suma, la colectividad en la que las partes desarrollan sus actividades dejaría de contar con unos ingresos públicos y fuentes de trabajo. Desde esta segunda perspectiva, se considera que las concentraciones de recuperación previenen un posible daño en los intereses de todos estos grupos.

$\left.3^{a}\right)$ La tercera y última es de índole económica y defiende la neutralidad de la concentración de salvamento para la libre competencia, es decir, la falta de relación causal entre el proyecto de concentración y el deterioro de la competencia en el mercado. Según esta forma de concebir la excepción que analizamos, la operación en la que participa una empresa crisis no lesiona la competencia, toda vez que la empresa en crisis no puede ser considerada una fuerza competitiva en el mercado. En rigor, la empresa adquirente utilizaría su nueva capacidad para aumentar la producción y, ulteriormente, para disminuir los precios, lo que favorecería a los consumidores. De ahí que, desde este punto de vista, la operación de concentración se conciba como la medida que más beneficia a la competencia, mientras que su prohibición obligaría a la entidad afectada a abandonar el mercado de referencia (HERRERO SUÁREZ, 200 Ib, pp. I50-I6I).

\subsection{Nudo}

A nuestro juicio, el fundamento de la doctrina de la empresa en crisis no ha de hacerse recaer exclusivamente en una de las argumentaciones a las que acabamos de aludir. El estudio de la 
práctica comunitaria nos permite apreciar que, a fin de valorar la licitud (compatibilidad) o ilicitud (incompatibilidad) de una operación de recuperación, la autoridad antitrust no sólo tiene en cuenta la concurrencia de los tres criterios fijados por las Directrices sobre Concentraciones Horizontales. Antes bien, la Comisión Europea también incluye en su evaluación otros factores tales como cuestiones sociales, regionales, industriales, de empleo e, incluso, las características del sector económico en el que se ejecuta la operación de concentración. Precisamente, en el informe de la OCDE de 2009, la Comisión tuvo a bien precisar que los criterios fijados en esta materia por las Directrices son relevantes para determinar si una de las partes es realmente una empresa en crisis, pero no pueden considerarse exclusivos ni exhaustivos. En su opinión, en dicho examen también son pertinentes otros elementos como la crisis económica y los mercados decrecientes -declining markets- (OCDE, 2009, p. 183).

La Comisión Europea ha seguido este enfoque en los cuatro asuntos en los que ha admitido la excepción de la empresa en crisis. En todos ellos, ciertamente, además de comprobar los requisitos relativos a la existencia de crisis financiera, inexistencia de alternativa y salida de los activos, llega a valorar otros aspectos diversos que, a la postre, también incidieron en la declaración de compatibilidad con el mercado único de dichas operaciones. En otras palabras, cabría decir que la Comisión se decidió finalmente por la aprobación de las concentraciones proyectadas por entender que de ellas resultaban múltiples ventajas: aumentaban la eficiencia económica, facultaban la redistribución de los activos de las empresas en crisis, preservaban los puestos de trabajo, alentaban la cohesión de los Estados miembros, garantizaban el mantenimiento de una dosis de competencia suficiente en las industrias relevantes $y$, en definitiva, prevenían un detrimento de los intereses de los consumidores (Decisión de la Comisión Europea, de I4 de diciembre de 1993, asunto IV/M.308 -Kali+Salz/MDK/Treuhand, considerandos 7I, 85 y 90; KOKKORIS, 2006, pp. 496 y 505-507; OCDE, 2009, pp. I87-I88).

De ahí que consideremos que la doctrina de la empresa en crisis no encuentra su razón de ser o fundamento únicamente en razones de índole económica, esto es, en la neutralidad de la operación de concentración desde el punto de vista antitrust ${ }^{14}$. Al contrario, para apreciar dicha neutralidad es indispensable tener en cuenta, por un lado, la especial situación de crisis que atraviesa la empresa objeto de adquisición y, por otro, que la operación de concentración se presente como la alternativa a la que se anudan mayores beneficios económicos, sociales, regionales y competitivos. $Y$ parece claro que estas últimas cuestiones no son estrictamente concurrenciales, como sí lo son, en cambio, la cuota de mercado, los niveles de concentración, la posición de las empresas o las barreras de entradas. Se trata, antes bien, de cuestiones extraconcurrenciales, que tienen cabida en la letra b) del apartado I del artículo 2 y en el considerando 23 del Reglamento 139/2004.

${ }^{114}$ En cambio, HERRERO SUÁREZ (2001b) se opone a esta postura, pues entiende que la doctrina de la failing company tiene como fundamento exclusivamente un fundamento económico; es decir, la falta de efectos anticompetitivos de la operación de concentración. Por ello, propone que ésta no debe utilizarse como una excepción afirmativa, sino como una cuestión más a considerar en la evaluación global de la evaluación de legalidad de la operación de concentración (pp. 159-161). Sin embargo, estimamos oportuno que esta solución no es la más adecuada, ya que al tratarse de una situación particular, esto es, una operación de concentración que, a la vista de un análisis meramente competitivo (criterios concurrenciales) resulta ilícita pero que en atención de la crisis de la empresa adquirida puede ser autorizada con el mercado único europeo. Las partes son las que cuentan con la información y las pruebas correspondientes sobre dicha situación y, por ende, sobre ellas recae la obligación de acreditarla. Este supuesto se asemeja a la excepción de la eficiencia económica donde las empresas partícipes tienen que demostrar y cuantificar los beneficios económicos que emanan de la operación de concentración a fin de contrarrestar los efectos anticompetitivos de la misma. 
Como se sabe, las disposiciones a las que acabamos de aludir facultan a la Comisión Europea a tener en cuenta en el análisis antitrust de las concentraciones de empresas la evolución del progreso técnico y económico, siempre que beneficie a los consumidores y no constituya un obstáculo para la competencia desproporcionado en lo que respecta a los fines a los que se dirige la operación de reestructuración: el rescate y saneamiento de la empresa en crisis. De hecho, si la autoridad antitrust sólo apreciara cuestiones meramente concurrenciales, la solución neutral y mejor para la competencia sería que las propias fuerzas del mercado presionaran la salida natural de la empresa en crisis y que el adquirente compitiera con el resto de operadores para suplir su demanda (MIRANDA SERRANO, L.M., 2000, pp. 68-7I; KOKKORIS, 2006, p. 506).

Junto a lo anterior, consideramos importante destacar que tanto el Derecho como la Economía son Ciencias Sociales que no pueden mostrarse imparciales o neutrales ante supuestos lesivos de los intereses de grupos entrelazados (los trabajadores, los accionistas, los acreedores y los consumidores de una empresa que adolece de graves dificultades económicas) y, especialmente, del bien común de la sociedad ${ }^{115}$. En esencia, ésta es la idea fundamental que subyace en la teoría de la empresa en crisis en el sistema europeo de control de concentraciones: la supervivencia de una empresa en crisis que redunda a favor tanto del desarrollo de una competencia efectiva como de todos los plurales intereses que se anudan a ella.

\subsection{Desenlace}

Por consiguiente, al juzgar la compatibilidad o incompatibilidad de una operación de concentración en la que participe una empresa en situación ruinosa, la autoridad antitrust no sólo debe analizar la concurrencia de los criterios formulados por las Directrices sobre Concentraciones Horizontales ${ }^{116}$. Al mismo tiempo, ha de apreciar los costes económicos y sociales aunados al cierre de la empresa en crisis, lo que exige tener en cuenta factores tales como la conservación de los puestos de trabajo, las inversiones de los accionistas, el pago a los acreedores $y$, en definitiva, el interés de la colectividad en la que opera la empresa que atraviesa graves dificultades financieras (MIRANDA SERRANO, 2000, pp. 66 y ss.).

\footnotetext{
${ }^{115}$ La objetividad en las ciencias sociales y, particularmente, en la economía proviene del principio de la Wertfreiheit que Max Weber propuso para alcanzar la objetividad en las ciencias sociales, que incidió particularmente en la economía. Ahora bien, el Derecho de defensa de la competencia y, en especial el sistema de control de concentraciones no es ajeno a esta visión de la objetividad o neutralidad. Justamente, el control de concentraciones ha sido la puerta de entrada del análisis económico y del uso herramientas económicas en el Derecho de la competencia como se puede apreciar con facilidad en el estudio de la posición de dominio colectiva donde los presupuestos de aplicación fijados en la sede del control de concentraciones se llevaron posteriormente al ámbito del artículo 102 TFUE -abuso de posición de dominio-. Ello no significa que tales herramientas y teorías no sean necesarias en la evaluación de compatibilidad/incompatibilidad de las operaciones de concentración, sino que se está dejando en un segundo plano la valoración jurídica de los resultados que proceden de los cálculos económicos. En este sentido, cabe destacar que el Derecho tiene como fin último la justicia, la equidad y el bien común en la sociedad. Si la autoridad de competencia, el jurista, los abogados de las partes quitan la mirada a los principios generales del Derecho los cuales son el faro de luz en toda valoración jurídica, esta rama se convertiría exclusivamente en la economía de la competencia. De esta manera se limitaría a una decisión económica del mercado libre y competitivo y los distintos sujetos beneficiados por el mantenimiento de una competencia efectiva quedarían desprotegidos (FONT GALÁN, 1994, pp. 19-23; CORTINA, 2012, pp. 8-9).

116 No obstante, HERRERO SUÁREZ (2001a; 2001b) apunta que en el análisis de compatibilidad/incompatibilidad de una operación sólo es posible tener en cuenta los beneficios tanto de índole económica como social en los supuestos en que no se define claramente una posición de dominio; por el contrario, no podrán compensarse lo efectos negativos dimanantes de la operación cuando tal posición no genere duda alguna (pp. 1943-1968; pp. 151-152). Como se ha expuesto en el presente apartado, no llegamos a compartir estos argumentos.
} 
Naturalmente, lo anterior no debe interpretarse en el sentido de que los alegatos de las partes han de basarse exclusivamente en cuestiones extraconcurrenciales. En rigor, debe existir un equilibro razonable entre todos los intereses que rodean la conservación de una empresa en grave penuria financiera. De ahí que en ciertas ocasiones las operaciones de concentración puedan funcionar como instrumentos anticrisis, pues coadyuvan a la conservación de organizaciones productivas que, de no ser por la operación, desaparecerían de un determinado sector económico, y todo ello con efectos muy positivos para los intereses de los consumidores y de la colectividad en general (MIRANDA SERRANO, 2000, p. 186) 117.

En consecuencia, creemos no equivocarnos al concluir que el fundamento de la doctrina de la failing company se encuentra en el propio sistema de economía social de mercado constitucionalizado en el marco de la Unión Europea que requiere, antes que nada, la existencia de empresas productivas, fuertes y eficientes -inciso 3 del artículo 3 TUE-. Por esta razón, el Derecho antitrust relaja o flexibiliza sus mecanismos sancionadores y represores en aquellas operaciones que, aunque restringen la competencia, se muestran, no obstante, como el único medio para lograr la recuperación de empresas en crisis. En otras palabras, por medio de estas operaciones se logra el aprovechamiento de empresas eficientes y productivas de las que resultan ganancias equitativas para los diferentes sujetos que las rodean: los accionistas, los trabajadores, los consumidores y, en suma, la sociedad. Se vislumbra así la ratio o fundamento de la excepción de empresa en crisis: la superioridad del valor-interés empresa productiva y eficiente, de la que derivan ventajas para la sociedad en general (consumidores, trabajadores, accionistas y acreedores), sobre el valor-interés de la libertad de competencia.

Comprobamos, por tanto, en la dirección en que se ha manifestado la doctrina especializada en la materia, que el Derecho de defensa de la competencia no es un valor absoluto, sino relativo, en el sentido de instrumental para la consecución de otros fines (FONT GALÁN, 1986, p. 287 y ss.; MIRANDA SERRANO, 1994, pp. 360 y ss.). Y es que, como hemos tratado de poner de relieve en las páginas anteriores, la doctrina de la failing firm defence incentiva el progreso técnico y socioeconómico mediante el expediente de autorizar una operación de reestructuración en atención a sus efectos beneficiosos. Ahora bien, como señala la doctrina, la tolerancia del Derecho antitrust ante estas operaciones ha de ser siempre excepcional, en el sentido de que sólo procede cuando las operaciones de concentración se presentan como indispensables y razonables para alcanzar los fines perseguidos: el saneamiento de empresas - 0 de sus divisionesen situación de fuerte crisis económica y financiera (MIRANDA SERRANO, 2000, pp. 62 y ss.).

\section{Bibliografía}

ALLENDESALAZAR CORCHO, R. (1992). La comisión prohíbe por primera vez una concentración notificada. Boletín de la Gaceta Jurídica de la CEE y de la Competencia, B-70, p. 79.

ARMENGOL I GASULL, O. (2009). Derecho de la competencia en tiempos de crisis. Gaceta Jurídica de la Unión Europea y de la Competencia, 8, 5-7.

ASSIMAKIS, K. \& JERAM, J. (20/4). Changing minds in changed circumstances: Aegan/Olympicc II and the failing firm defence. Journal of European Competition Law \& Practice, 9, 605-6I5.

\footnotetext{
${ }^{117}$ En consecuencia, en el Derecho antitrust europeo no sólo pueden funcionar excepcionalmente como medidas anticrisis los acuerdos entre empresas -cárteles de crisis o de saneamiento económicoy las ayudas públicas (ayudas de salvamento y de reestructuración), sino también las denominadas concentraciones de recuperación (COSTAS COMESAÑA, 1997, pp. 158 y ss.; idem, 2010, pp. 43 a 64).
} 
BACCARO, V. (2003). The Commission closes probe into pay-TV industry in Italy approving Newscorp/Telepiù merger deal. Competition Policy Newsletter, 2, 8-I I.

BACCARO, V. (2004). Failing firm defence and lack of causality: doctrine and practice in Europe o two closely related concepts. European Competition Law Review, I, I I-24.

BAUDENBACHER, C. \& BREMER, F. (20I0). European state aid and merger control in the financial crisis -from negative to positive integration. Journal of European Competition Law \& Practice, 4, 267-285.

BAVASSO, A. \& LINDSAY, A. (2007). Causation in EC Merger Control. Journal of Competition Law and Economics, 2, I8I-202.

BISHOP, S. \& WALKER, M. (2010). The economic of EC Competition Law: concepts, application and measurement ( $3^{\mathrm{a}}$ ed.). London: Sweet and Maxwell.

BRIONES, J., FOLGUERA, J., FONT, A. y NAVARRO, E. (1999). El control de concentraciones en la Unión Europea: la práctica de la Comisión Europea y las novedades introducidas en el Reglamento (CEE) 4064/89 por el Reglamento (CE) 1310/97. Madrid: Marcial Pons.

BRIONES, J., FOLGUERA, J., FONT, A. y NAVARRO, E. (2005). Merger Control in the European Union: law, economics and practice ( $2^{\mathrm{a}}$ ed.). New York: Oxford University Press.

CAFFARRA, C. \& COSCELLI, A. (2003). Merger to monopoly: NewsCorp/Telepiú. European Competition Law Review, I I, 625-627.

CALVIÑO, N. (2003). Algunas reflexiones para el debate sobre el tratamiento de las eficiencias en el análisis de las concentraciones empresariales. Anuario de la competencia, I, 67-92.

CALVO CARAVACA, A.L. \& CARRASCOSA GONZÁLEZ, J. (2006), Las concentraciones de empresas, Madrid: Colex.

CAPOBIANCO, A. (2010). An international perspective. Concurrences: Revue des Droits de la Concurrence, 2, 19-22.

DAVIS, P. \& COOPER, A. (20I0). On the evidence used to evaluate failing firm counterfactuals. Concurrences: Revue des Droits de la Concurrence, 2, 12-15.

COMISIÓN DE LAS COMUNIDADES EUROPEAS (1990). Decimonoveno informe sobre la política de competencia. Bruselas-Luxemburgo: Oficina de Publicaciones Oficiales de las Comunidades Europeas.

COMISIÓN EUROPEA (20I3a). Comunicado de prensa (Reference: IP/I3/804 Date: 2.9.2013) Mergers: Commission approves acquisition of Shell's Harburg refinery assests by Nynas $A B$ of Sweden. file://C:/Documents\%20and\%20Settings/Mario/Mis\%20documentos/Downloads/IP-I3804 EN.pdf.

COMISIÓN EUROPEA (20I3b). Comunicado de Prensa (Reference: IP/I3/927 Date:9.10.20I3) Mergers: Commission approves acquisition of Greek airline Olympic Air by Aegan Airlines. Recuperado de http://europa.eu/rapid/press-release IP-13-927 en.htm.

CORTINA, A. (20I2). Prólogo. Por una economía del bien común. Por ZAMAGNI, S. Madrid: Ciudad Nueva.

COSTAS COMESAÑA, J. (1997). Los cárteles de crisis: crisis económica y defensa de la competencia. Madrid: Marcial Pons.

COSTAS COMESAÑA. J. (2010). Cárteles de crisis. En MARTÍNEZ LAGE \& PETITBÒ JUAN (dirs.), El Derecho de la competencia en tiempos de crisis (pp. 43-64). Madrid: Marcial Pons.

FERNÁNDEZ, C. (2010). La supervivencia de las compañías en crisis. En MARTÍNEZ LAGE \& PETITBÒ JUAN (dirs.), El Derecho de la competencia en tiempos de crisis (PP. 127-I44). Madrid: Marcial Pons. 
FONT GALÁN, J.I. (1986). La libre competencia en la Comunidad Europea. Bolonia: Studia Albornotiana.

FONT GALÁN, J.I. (1994). Prólogo. Las concentraciones económicas de empresas: Derecho europeo y español. Por MIRANDA SERRANO, L.M. Madrid: La ley.

FONT GALÁN, J.I., MIRANDA SERRANO, L.M., PAGADOR LÓPEZ, J. y VELA TORRES, P.J. (2004). Viabilidad antitrust de las soluciones concursales de conservación de la empresa. Revista de Derecho Mercantil, 252, 463-532.

FOUNTOUKAKOS, K. \& GEARY, L., Time to bid farewell to the failing firm defense? Some Thoughts in the wake of Nynas/Shell and Olymplic/Aegean. Recuperado de https://www.competitionpolicyinternational.com/assets/Uploads/EuropeDecember2.pdf

GRAVE, C. (20I2). Merger control in the banking sector during the financial crisis. Zentrum furr Europäisches Wirtschaftsrecht, 178, I-I7.

HERRERO SUÁREZ, C. (200la). La excepción de eficiencia económica (efficiency defense) en el control de la concentración empresarial (análisis comparado entre el Derecho Antitrust estadounidense y el Derecho de la Competencia comunitario europeo). Revista de Derecho mercantil, 242, 1943-1968.

HERRERO SUÁREZ, C. (200lb). La excepción de empresa en crisis (failing firm defence) en el control de la concentración empresarial. Análisis comparado entre el Derecho antitrust estadounidense y el Derecho de la competencia comunitario europeo. Revista de Derecho bancario y bursátil, 84, 144-170.

HOVENKAMP, H. (20I I). Federal antitrust policy: the law of competition and its practice (4a ed.). United States of America: West Publishing.

JONES, A. \& SUFRIN, B. (20I I), EU Competition Law: text, cases and materials (4a ed.). New York: Oxford University Press.

KOKKORIS, I. (2006). Failing firm defence in the European Union: a panace for mergers?. European Competition Law Review, 9, 494-509.

KOKKORIS, I. (2007). Failing firm defence under the Clayton Act. European Competition Law Review, 3, I58-166.

KORAH, V. (2007). An Introductory Guide to EC Competition Law and Practice ( $9^{\mathrm{a}}$ ed.). United State: Hart Publishing.

LINDSAY, A. \& BERRIDGE, A. (20I2). The EU Merger Regulation: Substantive Issues (4a ed.). London: Sweet \& Maxwell.

MENDES PEREIRA, M. (2003). Recent consolidation in the European pay-TV sector. Competition Policy Newsletter, 2, 29-39.

MIRANDA SERRANO, L.M. (2000). La doctrina de la "failing company" y el Derecho europeo de concentraciones (las concentraciones de recuperación o saneamiento económico). Noticias de la Unión Europea, 185, 53-90.

MIRANDA SERRANO, L.M. (2003). Defensa de la competencia y adquisiciones de empresas en crisis en la Unión Europea. Revista Valenciana de Economía y Hacienda, 9, 183-216.

MIRANDA SERRANO, L.M. \& PÉREZ MOLINA, M.A. (20I4). El control de las concentraciones de empresas en la Unión Europea. Revista de Derecho Mercantil, 294, Pp. II5- 170.

NIELS, G., JENKIS, H. y KAVANAGH, J. (20II). Economics for competition lawyers. New York: Oxford Universty Press.

OCDE (1995), Failing firm defence. Recuperado de https://www.oecd.org/competition/mergers/ 1920253.pdf. 
OCDE (2009), The failing firm defence. Recuperado de http://www.oecd.org/daf/competition/mergers/4581082I.pdf.

PÉREZ MOLINA, M.A. (20I5). El criterio de la eficiencia económica (efficiency defence): contribuciones al progreso técnico y económico de relevancia antitrust en el control de concentraciones. Anuario de la competencia, I, 307-340.

REYNOLDS, N., MACRORY, S. y CHOWDHURY, M. (201 I). EU competition policy in the financial crisis: extraordinary measures. Fordham International Law Journal, 6, I692-I737.

ROSENTHAL, M. \& THOMAS, S. (2010). European Merger Control. München: C. H. Beck.

RUIZ PERIS, J.I. (20I0). Ayudas públicas e instituciones financieras. En CASITLLA GONZÁLEZ, F. \& MARIMÓN DURÁ, R. (coords.), Estudios de Derecho del mercado financiero: homenaje al profesor Vicente Cuñat Edo (pp. 785-808). Valencia: Universidad de Valencia.

SIGNES DE MESA, J.I. (2013), Derecho de la competencia y crisis económica. Él régimen de ayudas públicas y de concentraciones en el sector financiero. Navarra: Aranzadi.

$\begin{array}{ll}\begin{array}{l}\text { Abreviaturas } \\ \text { Ad ex. }\end{array} & \text { Ad exemplum } \\ \text { DOUE } & \text { Diario Oficial de la Unión Europea } \\ \text { P } & \text { Página } \\ \text { PP. } & \text { Páginas } \\ \text { TFUE } & \text { Tratado de Funcionamiento de la Unión Europea } \\ \text { TUE } & \text { Tratado de la Unión Europea }\end{array}$

